\title{
Application of Postbiotics Produced By Lactic Acid Bacteria in the Development of Active Food Packaging
}

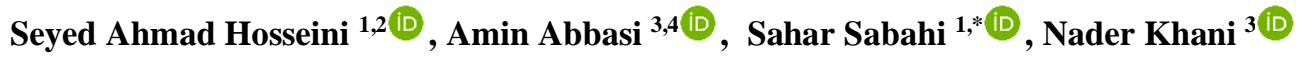 \\ 1 Department of Nutritional Sciences, School of Allied Medical Sciences, Ahvaz Jundishapur University of Medical \\ Sciences, Ahvaz, Iran \\ 2 Nutrition and Metabolic Diseases Research Center, Ahvaz Jundishapur University of Medical Sciences, Ahvaz, Iran \\ 3 Department of Food Science and Technology, Faculty of Nutrition \& Food Sciences, Tabriz University of Medical \\ Sciences, Tabriz, Iran \\ 4 Drug Applied Research Center, Tabriz University of Medical Sciences, Tabriz, Iran \\ * Correspondence: Sabahi-s@ajums.ac.ir (S.S.);
}

Scopus Author ID 57222359418

Received: 11.07.2021; Revised: 20.09.2021; Accepted: 25.09.2021; Published: 8.11.2021

\begin{abstract}
The use of postbiotics in the food industry is a common way to prevent food spoilage. Postbiotics are metabolites produced by probiotic bacteria that have many health effects. Non-toxicity and safety of postbiotics and their ability to inhibit microorganisms that cause food spoilage are the most important features of postbiotics in the use of these compounds in the food industry. In studies on postbiotics in the food industry, the use of these compounds as a way to control microbial spoilage of substances may interfere with the function (factors in the food matrix) in the function of postbiotics. Therefore, the use of postbiotics in the form of food packaging can be more effective. Therefore, due to their unique properties, postbiotics have received much attention in the food industry and can be used as a new approach in food packaging.
\end{abstract}

Keywords: probiotics; postbiotics; lactic acid bacteria; active packaging; antimicrobial activity.

(C) 2021 by the authors. This article is an open-access article distributed under the terms and conditions of the Creative Commons Attribution (CC BY) license (https://creativecommons.org/licenses/by/4.0/).

\section{Introduction}

In recent years, the collection of synthetic plastics has led to the expansion of a thoughtful environmental challenge [1]. About eight million metric tons of plastic end up in the ocean every year, threatening the surrounding environment and human health. Current packaging materials consume our limited natural resources and lead to a different kind of waste. On the other hand, pathogenic microbial contamination and infections through surface contact of solid materials are major public health concerns. Today, biodegradable films and coatings are recognized as a new strategy to solving this obstacle by making inexpensive, sufficient, and renewable elements. In these contexts, there has been a growing interest in the food packaging field to detect novel and safe biopolymers and natural antimicrobial compounds [2,3]. Lactic acid bacteria $(\mathrm{LAB})$ are a group of beneficial microbes whose derived metabolites possess a significantly vital role in food packaging. $\mathrm{LAB}$ is an essential part of food and is contained in the matrix of fermented food as safe and functional compounds, the consumption of which is directly related to health [4]. LAB in the matrix of fermented food uses suitable compounds (prebiotic-like elements) and then produces a variety of bioactive elements such as peptides, fatty acids, bacteriocins, and organic acids, which have important biological and physiological characteristics. The application of LAB in food packaging is a novel strategy to hinder the 
growth and development of foodborne pathogenic germs. The antimicrobial mechanism of the lob in the food matrix is through the reduction of $\mathrm{pH}$, the prevention of toxin production by pathogens, and the production of growth inhibitory compounds. In this regard, the main antimicrobial mechanisms of $\mathrm{LAB}$ are related to their unique action of secreting antimicrobial compounds (postbiotics) [4,5]. Some of the antimicrobial agents generated by LABs include lactic acids, acetic acids, hydrogen peroxide, reuterin, nisin, pediocin, or other bacteriocin-like substances, which among these antimicrobial agents, nisin has been approved by the Food and Drug Administration (FDA) and extensively apply in a various sector of the food industry as natural and safe antimicrobial agent. Despite the beneficial effects of LABs, the outcomes of some investigations have shown particular adverse clinical and technological influences of probiotics (e.g., metabolic disorders, including the generation of biogenic amines, the lack of clear clinical advice, and the lack of large and long-term clinical studies) [6]. In this regard, the use of metabolites LAB, which is known today as "postbiotic", is a suitable alternative method. [7]. The term postbiotic has been points to the use of nonviable cells or cell fractions, which, when administered in adequate amounts, confer a health benefit to the host [8]. This study aims to highlight the definitions and characteristics of postbiotics and their application inactive food packaging.

\section{Definition of Postbiotics}

Postbiotic refers to compounds such as protein compounds, organic acids, peptides, vitamins, and short-chain fatty acids produced by probiotic bacteria in the gut when feeding on fibrous compounds [9,10]. In recent years, the terms biogenic, abiotic, metabolic, paraprobiotic, and postbiotic have been used to describe non-living cells and their metabolites $[11,12]$. The following biotics include the major part of inactivated microbial cells (cell body), cell fractions (Teichoic acid, cell-specific peptidoglycans, and morbid endogenous cells), Enzymes, bacteriocins, and organic acids. They are secreted when microbial cells release and decompose in the host's gut. If they are received in sufficient quantities, they have a beneficial effect on the host [13]. When a probiotic bacterium feeds on prebiotic compounds, it produces postbiotics which is in the state of a natural method $[14,15]$. However, today these compounds are also produced in a laboratory method. These manners include heat treatment (TT), ultraviolet radiation (UV), formalin inactivation (FI), ionizing radiation (IR), high pressure (HP), and sonication [13]. Postbiotics have beneficial characteristics such as certain chemical arrangements, safe resources, and higher shelf life, and have immunomodulatory, antiinflammatory, cholesterol-lowering, antiproliferative, antioxidant, anti-hypertensive, and antiobesity characteristics [16]. The use of postbiotics in the food industry is increasing due to their special biological properties. Here we examine the biological properties of postbiotics.

\subsection{Safety aspects of postbiotics.}

The multiple human microbiota system plays an important role in human health and disease status. It is known that the plentiful bacterial population $\left(10^{14} \mathrm{CFU} / \mathrm{g}\right)$ in the intestine probably contributes to the immune system or metabolic roles and at the same time forms a defense system against various pathogens $[17,18]$. In addition, the high requirement for food and feed in reply to the increase in human population in developed countries makes the quality and safety of food and feed critical factors for the health and well-being of the community. However, probiotics are not considered completely safe for high-risk societies such as infants, 
the elderly, or the immunocompromised, in whom probiotics can cause side effects, systemic infections and gastrointestinal manifestations, and the transmission of antibiotic resistance genes from probiotics to normal microbiota [19,20]. Currently, various recently published research suggests that the viability of probiotics is not a major factor in the health benefits of probiotic bacteria [21], which can be useful in avoiding the risks associated with probiotic consumption.

Safety issues and administrative conductance related to postbiotics and related functional foods should be anticipated due to potential risks and safety issues. As is known, most probiotic foods include Lactobacillus spp. and/or Bifidobacterium spp., which have seldom been recognized in the etiology of clinical infections in humans [22]. Consequently, probiotic products on the market today are considered safe foods despite the risks associated with certain groups of people. With all of the above hazards connected with bacteria in food in mind, there are still beneficial bacteria such as LAB and Bifidobacteria that could work as valuable agents against the appearance of perishable pathogens and microorganisms as they compete with pathogenic bacteria and with the generation of biologic compounds can improve food safety and shelf life [23]. Considering all the reports available on the positive and negative effects of various bacteria, the postbiotic was introduced as a novel theory of functional food constituents to overcome the adverse influences of probiotics. However, it may be necessary to consider the probiotic cells as a safe resource and fermentation in the production of postbiotics [24], and the safety features when consuming postbiotics. Since the postbiotic application is a relatively novel strategy, to the best of our knowledge, there is no clinical or epidemiological proof of hazards correlated with its use, but in theory, there is no risk of infection due to the nonexistence of live microorganisms. Several in vitro and in vivo investigations assessed the influence of postbiotics on various cells, blood parameters, metabolic biomarkers, and intestinal mucosa, as shown below, with bacteria and microbial products [16,25]. Such investigations elucidate the potential mechanism of action and can also form a template for additional animal and human investigations to distinguish the use of postbiotics. Due to the restrictions in the transferability of in-vitro studies and the possibility of species-specific effects [26], in-vivo studies are therefore urgently recommended to verify the in-vitro effects of postbiotics. The in vitro model using the cancer cell lines Caco 2 and HT29 showed that the heat and postbiotics killed cells of a native strain of Lactobacillus plantarum A7 and a commercial strain of L. rhamnosus $\mathrm{GG}$ at concentrations of $2.5,5$, and 10 $\mathrm{mg} / \mathrm{ml}$ reduced the growth rate of the examined cell lines [27]. The cytotoxicity of the cell extracts of L. acidophilus LA102 and L. casei LC232 was evaluated in an in vitro model of Caco2, and HRT18 cell lines, and the outcomes revealed that the rate of inhibition of proliferation was 37\% (Caco2) and 68.5\% ( HRT18). for LA102 the inhibition rate was an additional $48 \%$ (Caco2) and $45.7 \%$ (HRT18) for LC232 at a concentration of $100 \mu \mathrm{g}$ extract $/ \mathrm{mL}$. The results obtained approved the IC50 values as follows: 1.6 and $2.5 \mu \mathrm{g} / \mathrm{ml}$ LA102 and 15.4 and $6.2 \mu \mathrm{g} / \mathrm{ml} \mathrm{LC232} \mathrm{against} \mathrm{Caco2} \mathrm{and} \mathrm{HRT18} \mathrm{[28].} \mathrm{In} \mathrm{a} \mathrm{further} \mathrm{in} \mathrm{vitro}$ study, the cytotoxicity of individual postbiotics generated by L. plantarum strains (I UL4, TL1, RS5, RI11, RG11, and RG14) in a concentration range of $0.47 \%$ to $30 \%$ (v / v ) was assessed on the various cancer cell lines. The results demonstrated the ability to induce inhibitory effects such as antiproliferative induction and apoptosis in malignant cells that were dose and timedependent [4]. With regard to the molecular signaling mechanisms, the antimetastatic and antiapoptotic effects of the HKSON fraction of L. reuteri were measured in a cancer stem cell model. The effects against metastases and apoptosis could be described by the downregulation 
of MMP9 and COX2 in accordance with the upregulation of TIMP1 so that it could be concluded that secretory macro-molecules are accountable for the recognized effects through modulation of various gene expressions [29]. A study by Cui et al. (2019) in a mouse model revealed that postbiotics $(0.2 \mathrm{ml}$ oral probe) from $L$. reuteri $\mathrm{ZJ} 617$ can ameliorate the acute damage induced by lipopolysaccharides in the liver. The ZJ617 supernatant used as a postbiotic was able to reduce inflammatory liver infiltration and serum biomarkers. The use of freshly weaned lambs as animal models showed that postbiotic supplementation $(0.9 \%$ postbiotic $L$. Plantarum RG14) was able to increase weight gain, feed intake, nutrient uptake, and nutrient digestibility, which reflects the ability of postbiotic to improve rumen fermentation and microbial activity in the gut [30]. Izuddin et al. reported that postbiotic supplementation $(0.9 \%)$ of L. plantarum RG14 in the diet of lambs after weaning led to a higher production of mucosal antibodies and antimicrobial peptides in the intestinal papillae, while the population of intestinal pathogens was lower than in the control group without postbiotics. The effects mentioned could be beneficial in reducing the cost of treatments and production losses because the animals' immune system is better prepared against several pathogens [31]. In a poultry type (broiler chicken), which was stimulated with the application of $\mathrm{Cl}$. perfringens, Johnson et al. (2019) mentioned that the management of postbiotics (7.5 g/L of clean ingesting water) diminishes pro-inflammatory responses and production of homeostatic-like responses [32]. Another investigation with broiler chickens confirmed that the inulin and postbiotic $(0.15 \%$ and $0.45 \%$ RG14) in the weight loss programs beneficially affected the animal's overall performance. Hence, the development in increase overall performance and populace of useful bacteria, in step with a discount withinside the populace of Enterobacteria and E. coli, become distinguished. Additionally, the extended acetic acid attention with related changes in ileal cytokine expression become additionally acquired in handled chickens [33]. Apart from various animal models for postbiotics, the peptides, peptidoglycan, cell-surface proteins, shortchain fatty acids, EPS, vitamins, lipopolysaccharides, and teichoic acids have been diagnosed because of the ability options materials for infectious illnesses withinside the discipline of aquaculture systems [33]. It is thought that the intestine epithelial barrier creates the primary protection barrier in opposition to the outside global related to unique pathogens, antigens, and dangerous substances. Consequently, any disorder withinside the barrier capability of the intestine epithelium (described as the leaky intestine) may want to open the gate and disclose the inner of the frame closer to more than one bad material and organism. Therefore, any materials with the potential to reinforce the intestinal barrier can be categorized as healthselling materials, and therefore, postbiotics can be taken into consideration as feasible candidates [34]. The supply of the useful outcomes of fermented ingredients at the gastrointestinal tract now no longer simplest comes from stay microorganisms due to the fact the goods from fermentation also can exert health-selling outcomes [35]. The underlined mechanisms regarding the outcomes of postbiotics on intestine barrier integrity have been addressed in various studies. The purification of two proteins known as p40 and p75 (based on the molecular weight) of postbiotics from L. rhamnosus GG resulted in explaining the possible mechanism of action associated with postbiotics. These proteins may serve as important players in different aspects like preventing TNF-induced damages, inhibition of apoptosis, and stimulation of intestinal epithelial cells proliferation [36]. Different pieces of evidence confirmed the importance of p40 and p75 as fundamental proteins in the function of probiotics and their metabolites $[37,38]$. Several studies had been designed for toddlers and adolescent volunteers due to the fact the hobby in probiotics and prebiotics began out to boom, stimulating 
the investments of the latest dietary techniques aiming at modulating the intestine microbiota and using postbiotics on dietary perspectives. Clinical reviews primarily based totally on the fermented infant's formulation with merchandise from B. breve C50 and $S$. thermophilus in a mixture with short-chain galactooligosaccharides and long-chain fructooligosaccharides showed the protection of the formulation in wholesome period newborns [39]. The nonviable lactobacilli merchandise is taken into consideration as a large part of postbiotic proposals in adults. Some research proved the protection of the usage of lactobacilli merchandise in adults, and the bulk of those research describes the useful results of postbiotics on gastrointestinal functioning and remedy of diarrhea [40]. The inactivated lifestyle medium from Lactobacillus and Lactococcus (drugs consistent with day) in adults (suggest age $53.4 \pm 17$.three years) with diarrhea confirmed higher overall performance indicated with the aid of using decrease ache scores, bloating, and the first-class of existence stepped forward after remedy. However, this takes a look at lacked the manipulate organization, and the authors in comparison it with the baseline statistics after 1 month of remedy [41]. Another take a look at centered on wholesome adults (20 to 70 years old) with a bent in the direction of constipation or extra actions of the bowel to check the results of postbiotics from Lactobacillus gasseri CP2305 as opposed to a placebo. The centered markers had been Bristol stool scale scores, output, and color tone. All the critiques confirmed nice consequences in postbiotic remedies and the organization with extra constipation confirmed higher consequences in comparison to the diarrhea organization. The evaluation of fecal samples indicated growth in propionic acid, butyric acid, and valeric acid, and Clostridium cluster IV in postbiotic-treated groups [40]. In conclusion, postbiotics may contribute to the host's wellbeing and convey the beneficial effects via different mechanisms, even though the underlined mechanism of action has not been fully understood. The aforementioned studies confirmed and suggested the safety of using postbiotics in appropriate doses and concentrations.

\subsection{Antimicrobial effects of postbiotics.}

Besides, the significant antimicrobial effect of postbiotics is another vital factor in its use in food packaging. The postbiotics used in the food packaging composition prevent the spoilage of food inside the package by microorganisms by preventing it from entering the food matrix [42]. Since most food spoilage occurs by bacteria, studies have focused on bacteria. Studies have shown that each postbiotic compound has a specific mechanism in inhibiting spoilage bacteria [42-44]. The primary antibacterial mechanism of postbiotics consists of acidifying the mobile cytoplasm and stopping power law and production, defeating the growth of pathogenic microorganisms through the formation of holes in cellular membranes, morphological and purposeful adjustments of touchy additives consisting of proteins and peptides through growing acidity withinside the bacterial cell membrane in addition to inducing the oxidation of bacterial cells. The production and use of antimicrobial and bioactive food films for food packaging is a growing research field [30,42]. The postbiotics cocktail includes a huge type of biologically active metabolites creating synergistic antimicrobial actions withinside the films and food products. Moreover, the purification procedure of postbiotics metabolites (e.g., bacteriocins) includes more expensive methods, which make the active film greater pricey for the food producers and consumers [45,46]. Therefore, postbiotics can serve as the ideal antimicrobial compound, and there may be a developing hobby withinside the fabrication of postbiotics-included antimicrobial active films at some point in current years. Among the postbiotic compounds of bacteriocins and exopolysaccharides, it has been used 
most in the production of packaging films. Studies in recent years show a good relationship between postbiotics and food packaging. For example, Sharaf et al. (2019) prepared chitosan nanoparticles containing postbiotics produced from seven LAB ( $L$. plantarum, L. helveticus, L. rhamnosus, L. reuteri, Streptococcus thermophiles, Enterococcus faecium, and L. lactis) and confirmed the antibacterial and antifungal activity of all active nanoparticles in Egyptian cheese [47]. In another study, Salvucci et al. (2019) produced postbiotics from E. Faecium and also their semi-purified bacteriocin extract as an antimicrobial agent in the formulation of triticale flour films.

When the postbiotics combination turned into integrated into the films, considerable growth in water solubility and opacity of films turned into found; nevertheless, the components did now no longer alternate the films' mechanical characteristics and water vapor permeability. Incorporating $1 \%(\mathrm{v} / \mathrm{v})$ of postbiotics or bacteriocin-wealthy extract created suitable antibacterial interest in triticale flour films. At the identical concentration, no considerable distinction was found among the antibacterial interest of postbiotics and bacteriocins extractloaded films [48]. Divsalar et al. (2018) organized cellulosic paper lined with chitosan-ZnO nanocomposite and used nisin $(500$ and $1,000 \mu \mathrm{g} / \mathrm{mL})$ as an antimicrobial agent in its structure. The incorporation of nisin furnished a robust antimicrobial impact on Listeria monocytogenes. Moreover, during 1-month storage at $4{ }^{\circ} \mathrm{C}$, no significant decrease was observed in the antimicrobial activity of films. They also evaluated the effect of the active films for the packaging of ultra-filtered white cheese and reported that films with $1,000 \mu \mathrm{g} / \mathrm{mL}$ of nisin were able to completely inactivate the initial counts of $L$. monocytogenes on the surface of the cheese after 14 days of storage at $4{ }^{\circ} \mathrm{C}$ [49-51].

\subsection{Reduction and degradation of chemical contaminants.}

Recently studies have shown that postbiotics have the potential to destroy chemical contaminants such as bisphenol A, pesticides, and mycotoxins. In this sense, several works are attentive to bisphenol A, which is a group of low-molecular-weight compounds responsible for possible adverse reactions after food use $[52,53]$. The bisphenol-a, accumulated in fermented foods, is mostly produced by microbial decarboxylation of amino acids[54]. For example, precursor amino acids such as tyrosine, lysine, ornithine, histidine, and tryptophan produce cadaverine, histamine, tyramine, putrescine, and tryptamine, respectively. Putrescine can be transformed into spermidine that can form spermine[55]. Bisphenol-a is usually found in foods such as fish, vegetables, meat, cheese, and wines. Some bisphenol-a, especially histamine, tyramine, putrescine, and cadaverine, are involved in variant physiological and toxicological problems in the human body. The main microbial groups associated with bisphenol-a making are some Gram-negatives (Enterobacter spp. and Pseudomonas spp.) and Gram-positive bacteria, for example, Staphylococcus spp and probiotics strains[43]. Some species of Streptococcus spp., Lactococcus spp., Pediococcus spp., and Lactobacillus spp. generally have decarboxylase enzymes and have been cited as accountable for bisphenol a, accumulation in fermented foods[56]. The bisphenol-a formation/accumulation in foods could be decreased by (a) limiting microbial growth utilizing irradiation, controlled atmosphere packaging, hydrostatic pressures, or food additives, and (b) using an amine-negative starter culture and/or amine oxidase [57]. On the other hand, many published works showed the bisphenol adegrading capability of probiotics strain [58], however as previously mentioned, the direct use of probiotics strain has some drawbacks. In another study, the researchers have been using postbiotics from probiotics to evaluate the bisphenol-a degradation on the food matrix and in 
in vitro conditions. The relationship between postbiotics and bisphenol degradation has been partially examined. The bisphenol a decreased capability of postbiotics may be connected to (a) prohibition of the growth of bisphenol A producing LAB, (b) direct degradation of bisphenol A by postbiotics, and (c) decrease of bisphenol a formation by changing environmental conditions (e.g., $\mathrm{pH}$ ) [59,60]. To understand the first strategy, the antimicrobial performance of postbiotics should be investigated by in vitro tests (i.e., agar disk and well 3406 diffusions, broth microdilution). The third scenario may be related to diamine oxidase and monoamine from LAB, which can be present in postbiotics and permeation of the bisphenol A degradation [61]. In another study, the researchers purified the thermostable amine oxidase mixture from $L$. plantarum CAU 3823 with a moderated possibility to degrade $40 \%$ of investigated bisphenol A (histamine, tyramine, putrescine, and cadaverine) in Chinese rice wine[56]. Amine oxidase was also identification in L.casei, L.plantarum [62], and L.curvatus [63]. Xie, Wang, Deng, and Xu (2016) investigated the performance of postbiotic and heattreated postbiotic from L. plantarum on cell growth and diamine manufacture by four aminepositive bacteria (Enterobacteria species). Both types of postbiotics remarkably reduced cell growth and diamine production in all species except for Enterobacter cloacae. When the initial $\mathrm{pH}$ value reduced from 6.5 to 4.5 , significant decreases in four amine-positive bacteria were found (except for E. cloacae in $\mathrm{pH}$ 6.5). In another study, postbiotics comprising diamine oxidase were more impressive than the lactobacillus bacteria strain (L. sakei) to degrade HIS in both model systems (phosphate buffer) and tuna soup [64]. L. curvatus $G$ - 1 was proposed as a potential candidate for bisphenol A control in fermented meat because it exhibited low BAs production and high bisphenol A degradability (more than 40\%) [65]. Therefore, the application of starter culture with amine oxidase capacity in food may be considered the main factor for the bacterial choice for the fermentation process. It is also recommended to monitor the amine oxidase amount of postbiotics before using them in degradation experiments. GarcíaRuiz et al. (2011) investigated the biodegradation capabilities of some wine-associated lactobacillus and postbiotics on some bisphenol $\mathrm{A}$ in culture media and wine. Most of the isolates ( $\mathrm{n}=80$ ), chiefly belonging to the $L A B s$ were able to degrade at least two of the three studied bisphenol A (HIS, TY, and PU) simultaneously[65]. They also reported that postbiotics from a LAB with high bisphenol A -degrading ability also revealed activity at an optimal $\mathrm{pH}$ of 4.7. Moreover, to avoid bisphenol A manufacture, postbiotics must be obtained from nondecarboxylase action of LAB [59], since decarboxylase enzymes may exhibit activity even later cell lysis and then, they may resist the commonly used food treatments (e.g., freezing, smoking, and heating) [56]. Toy et al. (2015) examined the BAs discount functionality of postbiotic (50\% and $25 \%$ concentrations) of four LAB strains in some foodborne pathogens in tyrosine decarboxylase broth. Postbiotics of Streptococcus thermophiles at each concentration suppresses the BAs manufacturing through Salmonella paratyphi A, while the best $50 \%$ of postbiotics acquired from $P$. acidophilus avoided the TY formation. Interestingly, the simultaneous utility of postbiotics from Streptococcus thermophilus and L. lactis subsp. lactis at 50\% concentrations decreased TY manufacturing through Staphylococcus aureus. It appears that, in this case, the short discount in $\mathrm{pH}$ might also additionally inhibit TY generation through the pathogens. Similarly, the PU-discount pastime of four LAB strains ( $P$. acidilactici, $L$. mesenteroides, $S$. thermophilus, and L. lactis subsp. lactis) changed into monitored in ornithine decarboxylase-enriched broth [59]. BAs reduction potential varied depending on the used strains, but $\geq$ a $65 \%$ reduction in accumulated PU was reported in all investigate postbiotics. The presence of AAs and reduction in $\mathrm{pH}$ are the main mechanisms behind $\mathrm{PU}$ decline. Owing 
to the protective function of some polyamines, the quantity of BAs increased in the presence of postbiotics [66]. In the food model, the combination of postbiotics from Pediococcus acidilactici with thyme extract exhibited varied activity on BAs formation in the fish fillet, depending on the type of BAs and storage time [67]. The outcomes of the works on this area confirmed that the capabilities of postbiotics vary drastically primarily based totally on the sort and concentrations of postbiotics, the form of Bas, and the BAs-generating pathogen [68]. Therefore, it is essential to accurately select the postbiotics from LAB strains in keeping with the preferred impact of generating BAs.

\subsection{Antibiofilm effect of postbiotics.}

Biofilms are a group of one or greater kinds of microorganisms that may develop at distinct levels. A biofilm is a complicated microbial network enclosed inside a polysaccharide or protein matrix [69]. Biofilms may result from microorganisms which include fungi and microorganisms. Both gram-positive and gram-negative bacteria revel in such ability [70]. Bacterial resistance withinside the biofilm section to antimicrobials is a main worldwide issue. The formation levels encompass a reversible and irreversible attachment to the outside and micro clone formation with the generation of exopolysaccharides [71]. In the food industry, irreversible biofilms and colony ingredients are very vital, and managing them is crucial for meals safety [72]. Biofilms shaped withinside the meals enterprise are greater immune to cleansing and disinfection processes. L. monocytogenes, Yersinia enterocolitis, Campylobacter jejuni, Staphylococcus aureus, and Bacillus cereus are vital biofilm-forming microorganisms withinside the meals enterprise [73]. Many strategies were used to manipulate and damage the biofilms shaped through microorganisms. Using postbiotics to kill biofilms is a brand new approach. In addition to having antimicrobial properties, postbiotics additionally have the belongings of destroying biofilms shaped through the microorganism. In current years, the impact of postbiotics on the removal of bacterial biofilms has been studied, which has yielded positive results [74]. In one study, the antibiofilm impact of postbiotics derived from the probiotic microorganism L.acidophilus LA5, L.casei 431, and L. salivarius on a biofilm shaped through $L$. monocytogenes at the polystyrene surfaces turned into observed. It validated that postbiotics damage biofilm formation. The authors set up that the presence of bacteriocin- and natural acid-primarily based postbiotics are the primary reason for the biofilm discount of $L$. monocytogenes. Therefore, postbiotics may be used as a device to manipulate and do away with biofilm formation through microorganisms withinside the meals enterprise [75].

\section{Postbiotic Food Packaging}

In the past, postbiotics were added directly to food, and the direct addition of postbiotics to food to increase shelf life was very common [76]. Despite the excessive antimicrobial ability of postbiotics, their direct use of the food matrix to increase its shelf life has a few disadvantages. The interplay of the complexation of postbiotics with the food additives can lessen their efficiency [77]. Additionally, the lower consistency of a few antimicrobial metabolites reasons their degradation and inactivation at some stage in meals processing. Lower miscibility of a few antimicrobial compounds with meals matrix is every other shortcoming that limits postbiotics applicability withinside the meals formulation. Economically, the embedding of a huge amount of the preservative compound withinside the indoor components of the meals matrix isn't suitable, due to the fact the microbial deterioration 
mainly the mold growth, initiates from the outside of meals [78,79]. A promising technique proposed to overcome those obstacles is using food packaging to prolong the shelf life of the foods. Active packaging is a system wherein the meal's product, the packaging material, and the environment engage positively to increase the shelf life of meals [80]. Postbiotics additionally have characteristics that make their use as a brand new compound in meal packaging favorable, together with being (a) maximum of them are usually identified as secure substances (GRAS); (b) they're now no longer poisonous on eukaryotic cells; (c) they may be without difficulty inactivated through digestive proteases and thus, do now no longer affect the intestine microbiota; (d) they're living in a huge variety of $\mathrm{pH}$; (e) they have got sturdy antimicrobial results in opposition to many foodborne pathogens and spoilage microorganisms even at low concentrations; and (f) most of the antimicrobial postbiotics have excessive thermal stability and their incorporation to the polymer matrix is possible even via extrusion and different heat-based processing methods [9,81]. Postbiotics contain various compounds such as organic acids, proteins, peptides, enzymes, and exopolysaccharides (EPS). Since most food spoilage occurs by microorganisms, especially bacteria, and due to the antibacterial properties of postbiotics, any of these compounds can be used in food packaging. Each of the postbiotic compounds inhibits food spoilage bacteria by a specific mechanism. The efficacy of postbiotics in food packaging is dependent on (a) the postbiotic type used in the packaging composition, (b) the type of target microorganism or contaminant, (c) concentration and form of application and (d) the food matrix characteristics. Among the above indicators, the type of postbiotics is very important.

\subsection{Postbiotic food packaging based on organic acids.}

Organic acids-based compounds are considered suitable antimicrobial factors [82]. Organic acids are referred to as one of the key postbiotics. Lactic acid (produced via way of means of bacterial fermentation processes) is to be had in isomers; $\mathrm{L}$ and $\mathrm{D}$, the previous of that are powerful in inhibiting pathogenicity [83]. Also, citric acid and acetic acid hinder the growth of pathogens via way of means of growing an acidic environment. Among natural acids, lactic acids ( $\mathrm{pka}=3.86)$ and acetic acids ( $\mathrm{pka}=4.76)$ hinder the growth of pathogens via way of means of lowering $\mathrm{pH}$ cost under in vitro or/and in vivo conditions [84]. The inhibitory impact of natural acids is associated with their impact on bacterial cell membranes. The foremost mechanisms right here include reducing the intracellular $\mathrm{pH}$ and membrane integrity [85]. The antimicrobial activity of natural acids may be related in ways. Acidification of cellular cytoplasm and prevention or/and the regulation of energy generation [84].

\subsection{Postbiotic food packaging based on the peptide.}

Antimicrobial peptides are produced through microorganisms. Peptides break microbes via pleiotropic (more than one action) mechanisms, along with microbial membrane degradation and the hindrance of macromolecule production [86]. Antimicrobial peptides are divided into ribosomal and non-ribosomal types. Peptides produced through the microorganism are ribosomal [87] and display robust antimicrobial interest in vitro through disrupting microbial membranes [88]. Peptides are typically found in all microorganisms. As mentioned, the primary goal of a few peptides is the cell membrane, while for others, it is the cytoplasm and delicate arrangements of microorganisms [89]. Antimicrobial mechanisms of the peptides include (a) developing acidity withinside the bacterial cell membrane, (b) developing physical 
holes that leak cellular content, (c) activating deadly strategies along with inducing hydrolases which have unfavorable results on the cell wall, (d) and damaging sensitive intracellular elements of the microbes [90].

\subsection{Postbiotic food packaging based on bacteriocins.}

Bacteriocins are peptides or proteins with antimicrobial activity produced by various bacteria, such as Archaebacteria and Eubacteria [85]. Bacteriocins have an excessive antimicrobial interest used for many years by people in fermented foods [91]. Bacteriocins are divided into steps with size, mechanism of action, and inhibitory spectrum. Bacteriocins have many useful effects, which include hindering the increase and improvement of gastrointestinal pathogens and being heat- and $\mathrm{pH}$-resistant. According to the outcomes of studies, the principal interest of bacteriocins is withinside the bacterial cytoplasmic membrane [92]. The antimicrobial mechanism of bacteriocins is directly related to their effects on the structure and function of bacterial peptides and their inhibitory activities on spores and pore formation on pathogenic cell membranes.

\section{Forms of Using Postbiotics in Active Food Packaging}

There are numerous sorts of the use of postbiotics in food active packaging systems such as (a) coating or adsorbing of a skinny layer of postbiotics onto the polymer surface; (b) immobilization of individual postbiotic (e.g., bacteriocins and enzymes) on polymers with the aid of using ion or covalent linkages; (c) direct incorporation of postbiotics in a packaging polymer matrix; and (d) lamination of the postbiotic-loaded active film among outside layers, which improve the postbiotics consistency and manage their migration [93].

\subsection{Application of individual postbiotic.}

Frist form of using postbiotics in food active packaging is the application of individual postbiotic produced by different LABs. Bacteriocins, as bioactive peptides with antimicrobial action generated through $\mathrm{LAB}$ are the maximum regularly used postbiotics metabolite withinside the meals industry. Usually, the low yield and excessive production charges restrict the application of natural bacteriocins at manufacturing levels [81]. Due to those reasons, researchers have proven high-quality hobbies in generating and comparing bacteriocin-loaded active packaging systems over the past decade. Among hundreds of present bacteriocins, nisin is the most famous and appreciably used bacteriocin within the fabrication of active antimicrobial films produced through a few unique strains of L. lactis. Divsalar et al. (2018) organized a cellulosic paper covered with chitosan-ZnO nanocomposite and used nisin (500 and $1,000 \mu \mathrm{g} / \mathrm{mL}$ ) as an AA in its structure. The incorporation of nisin supplied a sturdy antimicrobial impact on L. Monocytogenes. Moreover, in the course of the 1-month storage at $4{ }^{\circ} \mathrm{C}$, no considerable lower change into located withinside the antimicrobial pastime of films. They additionally evaluated the impact of the active films for the packaging of ultra-filtered white cheese and mentioned that films with $1,000 \mu \mathrm{g} / \mathrm{mL}$ of nisin have been capable of absolutely inactivating the preliminary counts of $L$. monocytogenes at the surface of the cheese after 14 days of storage at $4{ }^{\circ} \mathrm{C}$. Soto, Hernández-Iturriaga, Loarca-Piña, Luna-Bárcenas, and Mendoza (2019) organized nisin-loaded amaranth protein isolate/pullulan nanofibers films and located whole bactericidal activity in opposition to S. Typhimurium, L. monocytogenes, and $L$. mesenteroides in apple juice and fresh cheese [21]. Pediocin produced through Pediococcus 
spp is every other broadly studied bacteriocin, that's used withinside the instruction of antimicrobial films. The antimicrobial activity of nisin and pediocin-loaded starch-halloysite nanocomposite films in opposition to $\mathrm{L}$. monocytogenes and $\mathrm{Cl}$. Perfringens have been investigated [94]. According to their results, the antilisterial activity of pediocin changed better than the nisin, however, nisin exhibited a more antagonistic function on $\mathrm{Cl}$. perfringens. They additionally stated that incorporating halloysite helped manipulate the bacteriocins diffusion and better the antimicrobials retention withinside the polymer matrix. There are a few reviews on the usage of lactations withinside the system of active films. Enterocins of Enterococcus spp. are every other institution of purified individual postbiotic used withinside the fabrication of antimicrobial films. Gelatin films have been fabricated containing a combination of enterocins A, B, and P synthesized through Enterococcus faecium SM21 and prunin laurate as herbal antimicrobials[85]. According to their results, the enterocins-loaded film changed into powerful in opposition to L. monocytogenes, S. aureus, and B. cereus, and in all cases, a synergistic inhibitory action changed into located, while prunin laurate and enterocins have been concurrently introduced to the film. They located that the mechanical, thermal, and barrier characteristics of gelatin films have been no longer substantially laid low with active compounds incorporation.

\subsection{Application of postbiotics mixture.}

The postbiotics solution carries a huge type of biologically energetic metabolites stimulating synergistic antimicrobial activities withinside the films and food products [95]. Moreover, the purification procedure of postbiotics metabolites (e.g., bacteriocins and EPS) entails more expensive methods, making the active film greater highly priced for the food producers and consumers. Accordingly, postbiotics can act as the ideal AA, and there's a developing hobby withinside the fabrication of postbiotics-integrated antimicrobial active films throughout current years. As the primary file on postbiotics-integrated meals packaging films, Beristain-Bauza, Mani-López, Palou, and López-Malo (2016) delivered postbiotics from L. rhamnosus NRRL B-442 (6, 12, or $18 \mathrm{mg} / \mathrm{mL})$ in whey protein isolate and calcium caseinate films. According to their outcomes, the postbiotics at a concentration of $18 \mathrm{mg} / \mathrm{mL}$ had major antimicrobial hobby towards E. coli, L. monocytogenes, S. aureus, and S. Typhimurium without any unfavorable consequences at the bodily residences of each film. The water vapor permeability and puncture power of films decreased, and brown-colored films were acquired after postbiotics incorporation. In the second one, studies stated via way of means of the equal group, whey protein isolate-alginate films supplemented with postbiotics from L. sakei NRRL B-1917 become fabricated for packaging of beef cubes inoculated with E. coli or $L$. monocytogenes [96]. During the refrigerated storage, 1.4- and 2.3- $\log 10 \mathrm{CFU} / \mathrm{g}$ discounts of L.monocytogenes and E. coli have been found after a hundred and twenty and $36 \mathrm{hr}$, respectively. Sensorial reviews via way of means of panelists verified that there had been no meaningful variations among wrapped and unwrapped grilled red meat samples. In some other studies, approximately the utility of postbiotic active films on meat products, Rivas, Cayré, Campos, and Castro (2018) produced natural and synthetic casings (ovine, porcine, bovine, collagen, and cellulose casings) as vectors of postbiotics from L. curvatus ACU-1 and used for wrapping sausage meat paste. All postbiotics-loaded casings had appropriate antimicrobial activity towards L. monocytogenes. The authors proposed that each casing has been a powerful carrier of postbiotics and the active casings maintained their activity until the end of the trial. Recently, an antimicrobial meat wrapping nanopaper primarily based totally on bacterial 
nanocellulose integrated with postbiotics from L. plantarum has developed [42]. The nanocellulose films have been dipped into postbiotic answers with exceptional concentrations (5\% to $35 \%$ ) and at exceptional impregnation times (5 to $60 \mathrm{~min}$ ). The immobilization of postbiotics at the nanocellulose matrix produced a coherent community with reduced porosity. A meaningful reduction in tensile power and a growth in elongation capabilities of nanocellulose become found via way of means of the incorporation of postbiotics. The antimicrobial activity of nano papers towards L. monocytogenes elevated via way of means of growing postbiotics awareness and dipping time as much as $21.21 \%$ and $28 \mathrm{~min}$, respectively. The optimized nanopaper and managed nanocellulose become used to percent ground meat. The counts of L. monocytogenes withinside the floor meat extensively decreased ( 5 log cycles) after nine days of storage at $4{ }^{\circ} \mathrm{C}$. Moreover, the ground meat packed via way of means of postbiotics-activated nanocellulose reduced the whole mesophilic and psychrophilic bacterial counts and thiobarbituric acid values of meat samples. Postbiotics integrated active films have additionally been evaluated for the packaging of dairy products. Marques et al. (2017) produced a starch-primarily based antimicrobial active film containing postbiotics from L.curvatus P99 at concentrations (MIC: $15.6 \mu \mathrm{L} / \mathrm{mL}$ and minimal bactericidal awareness (MBC): $62.5 \mu \mathrm{L} / \mathrm{mL}$ ). In agar antagonistic assay, the postbiotics-loaded casing found out robust bactericidal activity towards L.monocytogen. After that, they packaged sliced "Prato" cheese with action films and studied the kinetics of antimicrobial movement of films throughout 10 days of storage. The outcomes indicated that each film has been powerful to lessen the $L$. monocytogenes Scott A counts in packaged "Prato" cheese, and the film containing the minimal bactericidal concentration (MBC) concentration of postbiotics remained underneath the restrict of detection $\left(2.7 \operatorname{logs} \mathrm{CFU} / \mathrm{g}\right.$ ) after 10 days of storage at $4{ }^{\circ} \mathrm{C}$, without displaying distinguishable consequences on sensory characteristics [97]. Sharaf et al. (2019) organized chitosan nanoparticles containing postbiotics constituted of seven LAB ( $L$. plantarum, $L$. helveticus, L. rhamnosus, L. reuteri, S. thermophiles, E. faecium, and L. lactis) and showed the antibacterial and antifungal activity of all active nanoparticles in Egyptian cheese. The postbiotics from L. lactis ATCC 11454, a nisin manufacturer strain, have been used as an AA to prepare sodium alginate/collagen or sodium carboxymethylcellulose/collagen-primarily based energetic films [98]. According to their outcomes, the incorporation of postbiotics adversely affected the physical characteristics of the films. The films' tensile power, extensibility, and transparency were reduced after postbiotics incorporation, and browncolored films with better water solubility have been acquired. However, the films exhibited sturdy antimicrobial activity on L. monocytogenes, S. aureus, and E. coli. Heat treatment of postbiotics (30 min at $90 \circ \mathrm{C}$ ), earlier than including it in the film, precipitated a discount of $14 \%$ to $26 \%$ withinside the overall antimicrobial performance of the films. They attributed such discount to the presence of heat-touchy bacteriocin-like inhibitory materials withinside the postbiotics. Salvucci et al. (2019) produced postbiotics from E. faecium and additionally their semi-purified bacteriocin extract as an AA withinside the components of triticale flour films. When the postbiotics combination becomes integrated into the films, meaningful growth in water solubility and opacity of films becomes found; however, the components no longer alternate the films' mechanical residences and water vapor permeability. Incorporating $1 \%$ $(\mathrm{v} / \mathrm{v})$ of postbiotics or bacteriocin-rich extract created accurate antibacterial activity in triticale flour films. At the equal concentration, no meaningful distinction between postbiotics' antibacterial activity and bacteriocins extract-loaded films is found. Generally, the literature evaluation shows that despite the fact that sturdy antimicrobial active films may be organized 
via way of means of incorporation of postbiotics to the packaging materials, the physicochemical residences of films can be adversely laid low with this incorporation and require an optimized postbiotics concentration to attain the right stability among antibacterial activity and thermomechanical residences of films [48]. To face this challenge, Bagde and Nadanathangam, (2019) used cellulose nanocrystals for the immobilization of postbiotics from $P$. acidilactici and E. faecium and integrated the activated cellulose nanocrystals into corn starch films. They advised higher stability of bacteriocins throughout the storage after immobilization on cellulose nanocrystals. In addition, the unfavorable impact of postbiotics at the mechanical and barrier residences of starch films become decreased after immobilization on cellulose nanofiller. They proposed that accurate antimicrobial packaging films with better thermal, mechanical, and barrier residences will be produced by immobilizing AAs on appropriate nano reinforcements earlier than including them into the film matrix [99].

\section{Microencapsulation of Postbiotics}

Protection of postbiotics towards damaging environments, which includes antimicrobial agents, chemicals, active oxygen in case of compulsory anaerobic microbes, bile salts, and excessive acidity, might be finished via using microencapsulation methods. Also, using strategies that include fluidized mattress drying, spray cooling, extrusion, chilling, molecular inclusion, spray drying, co-crystallization, and co-accretion might be possible to expand the processing of a forming capsule [54,100]. Choosing the method of the hobby depends on the material type, application, and release mechanism. Compounds that include carbohydrates, proteins, and lipids may be used to microencapsulate postbiotics [101]. Materials used for the microencapsulation of postbiotics should be non-toxic, highly soluble, heat-resistant, oxygen-permeable via the meals matrix, acid-resistant, and volatile at $\mathrm{pH}$ above $6[102,103]$. In the manner of encapsulating postbiotics, a biocompatible matrix should be used to encapsulate postbiotics towards elements that include $\mathrm{pH}$ and excessive temperature. The biocompatible matrix acts as a semi-permeable membrane and lets in the switch of postbiotics in directions. Studies in the latest years at the encapsulation of postbiotics have proven that encapsulation is an appropriate approach to guard those compounds towards irrelevant elements. In this regard, Le et al. (2019) encapsulated postbiotic (bacteriocin) produced via way of means of Lactobacillus plantarum isolated from Vietnamese fermented yogurt in alginate-gelatin (ALG-GEL). Also, its antimicrobial consequences withinside the presence of things which includes incubation temperature, mild $\mathrm{pH}$, and surfactants (Ethylene diamine tetraacetic acid (EDTA), sodium dodecyl sulfate (SDS), and twin) towards five indicator organisms, which include E. coli, Salmonella, S. aureus, L.monocytogenes, and Bacillus subtilis had been evaluated in meat. They determined that encapsulating postbiotics withinside the presence of those elements should save you the spoilage of red meat via way of means of pathogens. It appears that the microencapsulation of postbiotics may be a desirable manner to guard postbiotics. Using microencapsulation technology, postbiotics might be utilized in meals uncovered to excessive temperatures and low pH (e.g., vegetables) [104].

\section{Conclusions}

The use of postbiotics in the food industry is a common way to prevent food spoilage. Postbiotics are metabolites produced by probiotic bacteria that have many health effects. Nontoxicity and safety of postbiotics and their ability to inhibit microorganisms that cause food 
spoilage are the most important features of postbiotics in using these compounds in the food industry. In studies on postbiotics in the food industry, the use of these compounds as a way to control microbial spoilage of substances may interfere with the function (factors in the food matrix) in the function of postbiotics. Therefore, the use of postbiotics in the form of food packaging can be more effective. Therefore, due to their unique properties, postbiotics have received a lot of attention in the food industry and can be used as a new approach in food packaging. Future head-to-head trials are necessary to distinguish appropriate strains of parent cells, active compounds, biological function, optimal dosages and to examine their activities in developing active food packaging.

\section{Funding}

This research received no external funding.

\section{Acknowledgments}

The authors would like to express their thanks to the Research vice-chancellor of Ahvaz Jundishapur University of Medical Sciences for this study's financial support.

\section{Conflicts of Interest}

The authors declare that they have no conflicts of interest.

\section{References}

1. Alizadeh-Sani, M.; Ehsani, A.; Kia, E.M.; Khezerlou, A. Microbial gums: introducing a novel functional component of edible coatings and packaging. Applied microbiology and biotechnology 2019, 103, 6853-6866, https://doi.org/10.1007/s00253-019-09966-x.

2. Majeed, M.; Majeed, S.; Nagabhushanam, K.; Mundkur, L.; Rajalakshmi, H.; Shah, K.; Beede, K. Novel Topical Application of a Postbiotic, LactoSporin ${ }^{\circledR}$, in Mild to Moderate Acne: A Randomized, Comparative Clinical Study to Evaluate its Efficacy, Tolerability, and Safety. Cosmetics 2020, 7, 70, https://doi.org/10.3390/cosmetics7030070.

3. Pop, O.L.; Pop, C.R.; Dufrechou, M.; Vodnar, D.C.; Socaci, S.A.; Dulf, F.V.; Minervini, F.; Suharoschi, R. Edible Films and Coatings Functionalization by Probiotic Incorporation: A Review. Polymers 2020, 12, 12, https://doi.org/10.3390/polym12010012.

4. Wong, K.E.; Ngai, S.C.; Chan, K.-G.; Lee, L.-H.; Goh, B.-H.; Chuah, L.-H. Curcumin nanoformulations for colorectal cancer: a review. Frontiers in pharmacology 2019, 10, 152, https://doi.org/10.3389/fphar.2019.00152.

5. Akbari, M.R.; Haghighi, H.R.; Chambers, J.R.; Brisbin, J.; Read, L.R.; Sharif, S. Expression of antimicrobial peptides in cecal tonsils of chickens treated with probiotics and infected with Salmonella enterica serovar typhimurium. Clinical and Vaccine Immunology 2008, 15, 1689-1693, https://doi.org/10.1128/CVI.00242-08.

6. Tomar, S.K.; Anand, S.; Sharma, P.; Sangwan, V.; Mandal, S. Role of probiotics, prebiotics, synbiotics and postbiotics in inhibition of pathogens. The Battle against Microbial Pathogens: Basic Science, Technological Advances and Educational Programs; Méndez-Vilas, A., Ed 2015, 717-732.

7. Callon, C.; Arliguie, C.; Montel, M.-C. Control of Shigatoxin-producing Escherichia coli in cheese by dairy bacterial strains. Food microbiology 2016, 53, 63-70, https://doi.org/10.1016/j.fm.2015.08.009.

8. Homayouni Rad, A.; Aghebati Maleki, L.; Samadi Kafil, H.; Abbasi, A. Postbiotics: A novel strategy in food allergy treatment. Critical reviews in food science and nutrition 2021, 61, 492-499, https://doi.org/10.1080/10408398.2020.1738333. 
9. Rad, A.H.; Aghebati-Maleki, L.; Kafil, H.S.; Abbasi, A. Molecular mechanisms of postbiotics in colorectal cancer prevention and treatment. Critical reviews in food science and nutrition 2020, 1 17, https://doi.org/10.1080/10408398.2020.1765310.

10. Abbasi, A.; Sheykhsaran, E.; Kafil, H.S. Postbiotics: Science, Technology and Applications; Bentham Science Publishers 2021.

11. Homayouni Rad, A.; Aghebati Maleki, L.; Samadi Kafil, H.; Abbasi, A. Postbiotics: A novel strategy in food allergy treatment. Critical reviews in food science and nutrition 2020, 1-8, https://doi.org/10.1080/10408398.2020.1738333.

12. Abbasi, A.; Aghebati-Maleki, L.; Homayouni-Rad, A. The promising biological role of postbiotics derived from probiotic Lactobacillus species in reproductive health. Critical Reviews in Food Science and Nutrition 2021, 1-13, https://doi.org/10.1080/10408398.2021.1935701.

13. Rad, A.H.; Abbasi, A.; Kafil, H.S.; Ganbarov, K. Potential pharmaceutical and food applications of postbiotics: a review. Current pharmaceutical biotechnology 2020, https://doi.org/10.2174/1389201021666200516154833.

14. Rad, A.H.; Maleki, L.A.; Kafil, H.S.; Zavoshti, H.F.; Abbasi, A. Postbiotics as novel healthpromoting ingredients in functional foods. Health promotion perspectives 2020, 10, 3-4, https://doi.org/10.15171/hpp.2020.02.

15. Aghebati-Maleki, L.; Hasannezhad, P.; Abbasi, A.; Khani, N. Antibacterial, Antiviral, Antioxidant, and Anticancer Activities of Postbiotics: A review of Mechanisms and Therapeutic Perspectives 2021, https://doi.org/10.33263/BRIAC122.26292645.

16. Fathi-zavoshti, H.; Douroud, N.; Shahbazi, N.; Abbasi, A. Evaluating the role of postbiotics as a new generation of probiotics in health and diseases. Journal of Ardabil University of Medical Sciences 2020, $19, \quad 381-399, \quad$ https://jarums.arums.ac.ir/browse.php?a_code=A-10-1462$1 \&$ sid=1\&slc_lang=en.

17. Chong, C.Y.L.; Bloomfield, F.H.; O’Sullivan, J.M. Factors affecting gastrointestinal microbiome development in neonates. Nutrients 2018, 10, 274, https://doi.org/10.3390/nu10030274.

18. Mosca, F.; Gianni, M.L.; Rescigno, M. Can postbiotics represent a new strategy for NEC? $\begin{array}{lllll}\text { Probiotics and Child Gastrointestinal Health } & \text { 2019, }\end{array}$ https://doi.org/10.1007/5584_2018_314.

19. Sotoudegan, F.; Daniali, M.; Hassani, S.; Nikfar, S.; Abdollahi, M. Reappraisal of probiotics's safety in human. Food and Chemical Toxicology 2019, 129, 22-29, https://doi.org/10.1016/j.fct.2019.04.032.

20. Abbasi, A.; Aghebati-Maleki, A.; Aghebati-Maleki, L.; Yousefi, M. Probiotic intervention as a potential therapeutic for managing gestational disorders and improving pregnancy outcomes. Journal of Reproductive Immunology 2020, 103244, https://doi.org/10.1016/j.jri.2020.103244.

21. Aguilar-Toalá, J.; Garcia-Varela, R.; Garcia, H.; Mata-Haro, V.; González-Córdova, A.; VallejoCordoba, B.; Hernández-Mendoza, A. Postbiotics: An evolving term within the functional foods field. Trends in Food Science \& Technology 2018, 75, 105-114.

22. Plumed-Ferrer, C.; Kivelä, I.; Hyvönen, P.; Von Wright, A. Survival, growth and persistence under farm conditions of a Lactobacillus plantarum strain inoculated into liquid pig feed. Journal of applied microbiology 2005, 99, 851-858, https://doi.org/10.1111/j.1365-2672.2005.02666.x.

23. Gaggìa, F.; Mattarelli, P.; Biavati, B. Probiotics and prebiotics in animal feeding for safe food production. International journal of food microbiology 2010, 141, S15-S28, https://doi.org/10.1016/j.ijfoodmicro.2010.02.031.

24. Morniroli, D.; Vizzari, G.; Consales, A.; Mosca, F.; Giannì, M.L. Postbiotic Supplementation for Children and Newborn's Health. Nutrients 2021, 13, 781, https://doi.org/10.3390/nu13030781.

25. Angiari, S.; Runtsch, M.C.; Sutton, C.E.; Palsson-McDermott, E.M.; Kelly, B.; Rana, N.; Kane, H.; Papadopoulou, G.; Pearce, E.L.; Mills, K.H. Pharmacological activation of pyruvate kinase M2 inhibits CD4+ T cell pathogenicity and suppresses autoimmunity. Cell metabolism 2020, 31, 391405. e398, https://doi.org/10.1016/j.cmet.2019.10.015.

26. Karl, J.P.; Hatch, A.M.; Arcidiacono, S.M.; Pearce, S.C.; Pantoja-Feliciano, I.G.; Doherty, L.A.; Soares, J.W. Effects of psychological, environmental and physical stressors on the gut microbiota. Frontiers in microbiology 2018, 9, 2013, https://doi.org/10.3389/fmicb.2018.02013.

27. Sadeghi-Aliabadi, H.; Mohammadi, F.; Fazeli, H.; Mirlohi, M. Effects of Lactobacillus plantarum A7 with probiotic potential on colon cancer and normal cells proliferation in comparison with a commercial strain. Iranian Journal of Basic Medical Sciences 2014, 17, 815. 
28. Awaisheh, S.; Obeidat, M.; Al-Tamimi, H.; Assaf, A.; El-Qudah, J.; Rahahleh, R. In vitro cytotoxic activity of probiotic bacterial cell extracts against Caco-2 and HRT-18 colorectal cancer cells. Milk Science International-Milchwissenschaft 2016, 69, 33-37.

29. Maghsood, F.; Johari, B.; Rohani, M.; Madanchi, H.; Saltanatpour, Z.; Kadivar, M. Antiproliferative and antimetastatic potential of high molecular weight secretory molecules from probiotic Lactobacillus reuteri cell-free supernatant against human colon cancer stem-like cells (HT29-ShE). International Journal of Peptide Research and Therapeutics 2020, 1-13, https://doi.org/10.1007/s10989-020-10049-z.

30. Izuddin, W.I.; Loh, T.C.; Foo, H.L.; Samsudin, A.A.; Humam, A.M. Postbiotic L. plantarum RG14 improves ruminal epithelium growth, immune status and upregulates the intestinal barrier function in post-weaning lambs. Scientific reports 2019, 9, 1-10, https://doi.org/10.1038/s41598-019-460760 .

31. Izuddin, W.I.; Humam, A.M.; Loh, T.C.; Foo, H.L.; Samsudin, A.A. Dietary postbiotic lactobacillus plantarum improves serum and ruminal antioxidant activity and upregulates hepatic antioxidant enzymes and ruminal barrier function in post-weaning lambs. Antioxidants 2020, 9, 250, https://doi.org/10.3390/antiox9030250.

32. Johnson, C.N.; Kogut, M.H.; Genovese, K.; He, H.; Kazemi, S.; Arsenault, R.J. Administration of a postbiotic causes immunomodulatory responses in broiler gut and reduces disease pathogenesis $\begin{array}{llllll}\text { following } & \text { challenge. } & \text { Microorganisms } & \text { 2019, } & 7, & \text { 268, }\end{array}$ https://doi.org/10.3390/microorganisms7080268.

33. Kareem, K.; Loh, T.; Foo, H.; Asmara, S.; Akit, H. Influence of postbiotic RG14 and inulin combination on cecal microbiota, organic acid concentration, and cytokine expression in broiler chickens. Poultry science 2017, 96, 966-975, https://doi.org/10.3382/ps/pew362.

34. Anderson, R.C. Are Postbiotics the Long Sought-After Solution for a Leaky Gut? The Journal of nutrition 2019, 149, 1873-1874, https://doi.org/10.1093/jn/nxz171.

35. Maguire, M.; Maguire, G. Gut dysbiosis, leaky gut, and intestinal epithelial proliferation in neurological disorders: towards the development of a new therapeutic using amino acids, prebiotics, probiotics, and postbiotics. Reviews in the Neurosciences 2019, 30, 179-201, https://doi.org/10.1515/revneuro-2018-0024.

36. Cicenia, A.; Scirocco, A.; Carabotti, M.; Pallotta, L.; Marignani, M.; Severi, C. Postbiotic activities of lactobacilli-derived factors. Journal of clinical gastroenterology 2014, 48, S18-S22, https://doi.org/10.1097/MCG.0000000000000231.

37. Bermudez-Brito, M.; Plaza-Díaz, J.; Muñoz-Quezada, S.; Gómez-Llorente, C.; Gil, A. Probiotic mechanisms of action. Annals of Nutrition and Metabolism 2012, 61, 160-174, https://doi.org/10.1159/000342079.

38. Karimi, N.; Jabbari, V.; Nazemi, A.; Ganbarov, K.; Karimi, N.; Tanomand, A.; Karimi, S.; Abbasi, A.; Yousefi, B.; Khodadadi, E. Thymol, cardamom and Lactobacillus plantarum nanoparticles as a functional candy with high protection against Streptococcus mutans and tooth decay. Microbial pathogenesis 2020, 148, 104481, https://doi.org/10.1016/j.micpath.2020.104481 .

39. Wegh, C.A.; Geerlings, S.Y.; Knol, J.; Roeselers, G.; Belzer, C. Postbiotics and their potential applications in early life nutrition and beyond. International journal of molecular sciences $\mathbf{2 0 1 9}$, 20, 4673, https://doi.org/10.3390/ijms20194673.

40. Sawada, D.; Sugawara, T.; Ishida, Y.; Aihara, K.; Aoki, Y.; Takehara, I.; Takano, K.; Fujiwara, S. Effect of continuous ingestion of a beverage prepared with Lactobacillus gasseri CP2305 inactivated by heat treatment on the regulation of intestinal function. Food Research International 2016, 79, 33-39, https://doi.org/10.1016/j.foodres.2015.11.032.

41. Tarrerias, A.; Costil, V.; Vicari, F.; Letard, J.; Adenis-Lamarre, P.; Aisene, A.; Batistelli, D.; Bonnaud, G.; Carpentier, S.; Dalbies, P. The effect of inactivated Lactobacillus LB fermented culture medium on symptom severity: observational investigation in 297 patients with diarrheapredominant irritable bowel syndrome. Digestive Diseases 2011, 29, 588-591, https://doi.org/10.1159/000332987.

42. Yordshahi, A.S.; Moradi, M.; Tajik, H.; Molaei, R. Design and preparation of antimicrobial meat wrapping nanopaper with bacterial cellulose and postbiotics of lactic acid bacteria. International journal of food microbiology 2020, 321, 108561, https://doi.org/10.1159/000332987.

43. Molaei, R.; Tajik, H.; Moradi, M. Magnetic solid phase extraction based on mesoporous silicacoated iron oxide nanoparticles for simultaneous determination of biogenic amines in an Iranian traditional dairy product; Kashk. Food Control 2019, 101, 1-8, https://doi.org/10.1016/j.foodcont.2019.02.011. 
44. Rad, A.; Abbasi, A.; Javadi, A.; Pourjafar, H.; Javadi, M.; Khaleghi, M. Comparing the microbial quality of traditional and industrial yoghurts. Biointerface Research in Applied Chemistry 2020, 10, 6020-6025.

45. Cazón, P.; Vázquez, M. Bacterial cellulose as a biodegradable food packaging material: a review. Food Hydrocolloids 2020, 106530, https://doi.org/10.1016/j.foodhyd.2020.106530.

46. Abbasi, A.; Hajipour, N.; Hasannezhad, P.; Baghbanzadeh, A.; Aghebati-Maleki, L. Potential in vivo delivery routes of postbiotics. Critical Reviews in Food Science and Nutrition 2020, 1-39, https://doi.org/10.1080/10408398.2020.1865260.

47. Sharaf, O.M.; Al-Gamal, M.S.; Ibrahim, G.A.; Dabiza, N.M.; Salem, S.S.; El-ssayad, M.F.; Youssef, A.M. Evaluation and characterization of some protective culture metabolites in free and nano-chitosan-loaded forms against common contaminants of Egyptian cheese. Carbohydrate polymers 2019, 223, 115094, https://doi.org/10.1016/j.carbpol.2019.115094.

48. Salvucci, E.; Rossi, M.; Colombo, A.; Pérez, G.; Borneo, R.; Aguirre, A. Triticale flour films added with bacteriocin-like substance (BLIS) for active food packaging applications. Food Packaging and Shelf Life 2019, 19, 193-199, https://doi.org/10.1016/j.fpsl.2018.05.007.

49. Divsalar, E.; Tajik, H.; Moradi, M.; Forough, M.; Lotfi, M.; Kuswandi, B. Characterization of cellulosic paper coated with chitosan-zinc oxide nanocomposite containing nisin and its application in packaging of UF cheese. International journal of biological macromolecules 2018, 109, 13111318, https://doi.org/10.1016/j.ijbiomac.2017.11.145.

50. Homayouni Rad, A.; Samadi Kafil, H.; Fathi Zavoshti, H.; Shahbazi, N.; Abbasi, A. Therapeutically effects of functional postbiotic foods. Clinical Excellence 2020, 10, 33-52.

51. Abbasi, A.; Rad, A.H.; Ghasempour, Z.; Sabahi, S.; Kafil, H.S.; Hasannezhad, P.; Rahbar Saadat, Y.; Shahbazi, N. The biological activities of postbiotics in gastrointestinal disorders. Critical $\begin{array}{lllll}\text { Reviews in Food Science and } & \text { Nutrition }\end{array}$ https://doi.org/10.1080/10408398.2021.1895061.

52. Czajkowska-Mysłek, A.; Leszczyńska, J. Risk assessment related to biogenic amines occurrence in ready-to-eat baby foods. Food and Chemical Toxicology 2017, 105, 82-92, https://doi.org/10.1016/j.fct.2017.03.061.

53. Leylabadlo, H.E.; Heravi, F.S.; Soltani, E.; Abbasi, A.; Kafil, H.S.; Parsaei, M.; Sanaie, S.; Ahmadian, Z.; Ghotaslou, R. The role of gut microbiota in the treatment of irritable bowel syndrome. Reviews in Medical Microbiology 2021.

54. Mah, J.-H.; Park, Y.K.; Jin, Y.H.; Lee, J.-H.; Hwang, H.-J. Bacterial production and control of biogenic amines in Asian fermented soybean foods. Foods 2019, 8, 85, https://doi.org/10.3390/foods8020085.

55. Papageorgiou, M.; Lambropoulou, D.; Morrison, C.; Kłodzińska, E.; Namieśnik, J.; PłotkaWasylka, J. Literature update of analytical methods for biogenic amines determination in food and beverages. TrAC Trends in Analytical Chemistry 2018, 98, 128-142, https://doi.org/10.1016/j.trac.2017.11.001.

56. Barbieri, F.; Montanari, C.; Gardini, F.; Tabanelli, G. Biogenic amine production by lactic acid bacteria: A review. Foods 2019, 8, 17, https://doi.org/10.3390/foods8010017.

57. Naila, A.; Flint, S.; Fletcher, G.; Bremer, P.; Meerdink, G. Control of biogenic amines in foodexisting and emerging approaches. Journal of food science 2010, 75, R139-R150, https://doi.org/10.1111/j.1750-3841.2010.01774.x.

58. García-Ruiz, A.; González-Rompinelli, E.M.; Bartolomé, B.; Moreno-Arribas, M.V. Potential of wine-associated lactic acid bacteria to degrade biogenic amines. International journal of food microbiology 2011, 148, 115-120, https://doi.org/10.1016/j.ijfoodmicro.2011.05.009.

59. Ozogul, F.; Tabanelli, G.; Toy, N.; Gardini, F. Impact of cell-free supernatant of lactic acid bacteria on putrescine and other polyamine formation by foodborne pathogens in ornithine decarboxylase broth. Journal of agricultural and food chemistry 2015, 63, 5828-5835, https://doi.org/10.1021/acs.jafc.5b02410.

60. Homayouni-rad, A.; Oroojzadeh, P.; Abbasi, A. The Effect of Yeast Kluyveromyces marxianus as a Probiotic on the Microbiological and Sensorial Properties of Set Yoghurt during Refrigerated Storage. Journal of Ardabil University of Medical Sciences 2021, 20, 254-268.

61. García-Ruiz, J.M.; López-Moreno, J.I.; Vicente-Serrano, S.M.; Lasanta-Martínez, T.; Beguería, S. Mediterranean water resources in a global change scenario. Earth-Science Reviews 2011, 105, 121 139, https://dx.doi.org/10.1016/j.earscirev.2011.01.006. 
62. Fadda, S.; Vignolo, G.; Oliver, G. Tyramine degradation and tyramine/histamine production by lactic acid bacteria and Kocuria strains. Biotechnology Letters 2001, 23, 2015-2019, https://doi.org/10.1023/A:1013783030276.

63. Li, M.; van Esch, B.C.; Henricks, P.A.; Folkerts, G.; Garssen, J. The anti-inflammatory effects of short chain fatty acids on lipopolysaccharide-or tumor necrosis factor $\alpha$-stimulated endothelial cells via activation of GPR41/43 and inhibition of HDACs. Frontiers in pharmacology 2018, 9, 533, https://doi.org/10.3389/fphar.2018.00533.

64. Naila, A.; Flint, S.; Fletcher, G.; Bremer, P.; Meerdink, G. Histamine degradation by diamine oxidase, Lactobacillus and Vergibacillus halodonitrificans Nai18. Journal of Food Processing and Technology 2012, 3, https://doi.org/10.4172/2157-7110.1000158.

65. Freiding, S.; Gutsche, K.A.; Ehrmann, M.A.; Vogel, R.F. Genetic screening of Lactobacillus sakei and Lactobacillus curvatus strains for their peptidolytic system and amino acid metabolism, and comparison of their volatilomes in a model system. Systematic and Applied Microbiology 2011, 34, 311-320, https://doi.org/10.1016/j.syapm.2010.12.006.

66. Özogul, F.; Toy, N.; Özogul, Y. The impact of the cell-free solution of lactic acid bacteria on cadaverine production by Listeria monocytogenes and Staphylococcus aureus in lysinedecarboxylase broth. International Journal of Nutrition and Food Engineering 2015, 9, 309-317.

67. Kuley, E.; Durmus, M.; Ucar, Y.; Kosker, A.R.; Tumerkan, E.T.A.; Regenstein, J.M.; Ozogul, F. Combined effects of plant and cell-free extracts of lactic acid bacteria on biogenic amines and bacterial load of fermented sardine stored at $3 \pm 1^{\circ} \mathrm{C}$. Food bioscience 2018, 24, 127-136.

68. Özogul, F.; Toy, N.; Özogul, Y.; Hamed, I. Function of cell-free supernatants of Leuconostoc, Lactococcus, Streptococcus, Pediococcus strains on histamine formation by foodborne pathogens in histidine decarboxylase broth. Journal of Food Processing and Preservation 2017, 41, e13208.

69. Urish, K.L.; DeMuth, P.W.; Kwan, B.W.; Craft, D.W.; Ma, D.; Haider, H.; Tuan, R.S.; Wood, T.K.; Davis, C.M. Antibiotic-tolerant Staphylococcus aureus biofilm persists on arthroplasty materials. Clinical Orthopaedics and Related Research ${ }^{\circledR}$ 2016, 474, 1649-1656, https://doi.org/10.1007/s11999-016-4720-8.

70. Miao, J.; Liang, Y.; Chen, L.; Wang, W.; Wang, J.; Li, B.; Li, L.; Chen, D.; Xu, Z. Formation and development of Staphylococcus biofilm: with focus on food safety. Journal of Food Safety 2017, 37, e12358, https://doi.org/10.1111/jfs.12358.

71. Przekwas, J.; Wiktorczyk, N.; Budzyńska, A.; Wałecka-Zacharska, E.; Gospodarek-Komkowska, E. Ascorbic Acid Changes Growth of Food-Borne Pathogens in the Early Stage of Biofilm Formation. Microorganisms 2020, 8, 553, https://doi.org/10.3390/microorganisms8040553.

72. Andrade, J.C.; João, A.L.; Alonso, C.d.S.; Barreto, A.S.; Henriques, A.R. Genetic Subtyping, Biofilm-Forming Ability and Biocide Susceptibility of Listeria monocytogenes Strains Isolated from a Ready-to-Eat Food Industry. Antibiotics 2020, 9, 416, https://doi.org/10.3390/antibiotics9070416.

73. Shi, X.; Zhu, X. Biofilm formation and food safety in food industries. Trends in Food Science \& Technology 2009, 20, 407-413, https://doi.org/10.1016/j.tifs.2009.01.054.

74. Sharma, V.; Harjai, K.; Shukla, G. Effect of bacteriocin and exopolysaccharides isolated from probiotic on P. aeruginosa PAO1 biofilm. Folia microbiologica 2018, 63, 181-190, https://doi.org/10.1007/s12223-017-0545-4.

75. Moradi, M.; Mardani, K.; Tajik, H. Characterization and application of postbiotics of Lactobacillus spp. on Listeria monocytogenes in vitro and in food models. LWT 2019, 111, 457-464, https://doi.org/10.1016/j.lwt.2019.05.072.

76. Gómez-Sala, B.; Herranz, C.; Díaz-Freitas, B.; Hernández, P.E.; Sala, A.; Cintas, L.M. Strategies to increase the hygienic and economic value of fresh fish: Biopreservation using lactic acid bacteria of marine origin. International journal of food microbiology 2016, 223, 41-49, https://doi.org/10.1016/j.ijfoodmicro.2016.02.005.

77. Hamad, G.; Botros, W.; Hafez, E. Combination of probiotic filtrates as antibacterial agent against selected some pathogenic bacteria in milk and cheese. Int J Dairy Sci 2017, 12, 368-376, https://doi.org/10.3923/ijds.2017.368.376.

78. Dunand, E.; Burns, P.; Binetti, A.; Bergamini, C.; Peralta, G.H.; Forzani, L.; Reinheimer, J.; Vinderola, G. Postbiotics produced at laboratory and industrial level as potential functional food ingredients with the capacity to protect mice against Salmonella infection. Journal of applied microbiology 2019, 127, 219-229, https://doi.org/10.1111/jam.14276. 
79. Vilela, C.; Kurek, M.; Hayouka, Z.; Röcker, B.; Yildirim, S.; Antunes, M.D.C.; Nilsen-Nygaard, J.; Pettersen, M.K.; Freire, C.S. A concise guide to active agents for active food packaging. Trends in Food Science \& Technology 2018, 80, 212-222.

80. O'bryan, C.; Crandall, P.; Ricke, S.; Ndahetuye, J.; TAYLOR, T. 7-Lactic acid bacteria (LAB) as antimicrobials in food products: Analytical methods and applications. Handbook of Natural Antimicrobials for Food Safety and Quality 2015, 137-151, https://doi.org/10.1016/B978-1-78242034-7.00007-4.

81. Santos, J.C.; Sousa, R.C.; Otoni, C.G.; Moraes, A.R.; Souza, V.G.; Medeiros, E.A.; Espitia, P.J.; Pires, A.C.; Coimbra, J.S.; Soares, N.F. Nisin and other antimicrobial peptides: Production, mechanisms of action, and application in active food packaging. Innovative Food Science \& Emerging Technologies 2018, 48, 179-194.

82. Baghban-Kanani, P.; Hosseintabar-Ghasemabad, B.; Azimi-Youvalari, S.; Seidavi, A.; Ragni, M.; Laudadio, V.; Tufarelli, V. Effects of using Artemisia annua leaves, probiotic blend, and organic acids on performance, egg quality, blood biochemistry, and antioxidant status of laying hens. The Journal of Poultry Science 2019, 56, 120-127, https://doi.org/10.2141/jpsa.0180050.

83. Baird, B.; Lucia, L.; Acuff, G.; Harris, K.; Savell, J. Beef hide antimicrobial interventions as a means of reducing bacterial contamination. Meat science 2006, 73, 245-248, https://doi.org/10.1016/j.meatsci.2005.11.023.

84. Mani-López, E.; García, H.; López-Malo, A. Organic acids as antimicrobials to control Salmonella in meat and poultry products. Food Research International 2012, 45, 713-721.

85. Šušković, J.; Kos, B.; Beganović, J.; Leboš Pavunc, A.; Habjanič, K.; Matošić, S. Antimicrobial activity-the most important property of probiotic and starter lactic acid bacteria. Food Technology and Biotechnology 2010, 48, 296-307.

86. Waghu, F.H.; Idicula-Thomas, S. Collection of antimicrobial peptides database and its derivatives: Applications and beyond. Protein Science 2020, 29, 36-42, https://doi.org/10.1002/pro.3714.

87. Makarova, K.S.; Wolf, Y.I.; Karamycheva, S.; Zhang, D.; Aravind, L.; Koonin, E.V. Antimicrobial peptides, polymorphic toxins, and self-nonself recognition systems in Archaea: an untapped armory for intermicrobial conflicts. MBio 2019, 10, e00715-00719, https://doi.org/10.1128/mBio.0071519.

88. Hanson, M.A.; Dostalova, A.; Ceroni, C.; Poidevin, M.; Kondo, S.; Lemaitre, B. Synergy and remarkable specificity of antimicrobial peptides in vivo using a systematic knockout approach. Elife 2019, 8, e44341, https://doi.org/10.7554/eLife.44341.

89. Miller, S. Antimicrobial fusion proteins comprising an endolysin and an amphipathic peptide segment. 2019.

90. Zasloff, M. Antimicrobial peptides of multicellular organisms. nature 2002, 415, 389-395, https://doi.org/10.1038/415389a.

91. O'Connor, P.M.; Kuniyoshi, T.M.; Oliveira, R.P.; Hill, C.; Ross, R.P.; Cotter, P.D. Antimicrobials for food and feed; a bacteriocin perspective. Current Opinion in Biotechnology 2020, 61, 160-167, https://doi.org/10.1016/j.copbio.2019.12.023.

92. Gálvez, A.; Abriouel, H.; López, R.L.; Omar, N.B. Bacteriocin-based strategies for food biopreservation. International journal of food microbiology 2007, 120, 51-70, https://doi.org/10.1016/j.ijfoodmicro.2007.06.001.

93. Moradi, M.; Kousheh, S.A.; Almasi, H.; Alizadeh, A.; Guimarães, J.T.; Yılmaz, N.; Lotfi, A. Postbiotics produced by lactic acid bacteria: The next frontier in food safety. Comprehensive Reviews in Food Science and Food Safety 2020, https://doi.org/10.1111/1541-4337.12613.

94. Meira, S.M.M.; Zehetmeyer, G.; Werner, J.O.; Brandelli, A. A novel active packaging material based on starch-halloysite nanocomposites incorporating antimicrobial peptides. Food Hydrocolloids 2017, 63, 561-570.

95. Bali, V.; Panesar, P.S.; Bera, M.B.; Kennedy, J.F. Bacteriocins: recent trends and potential applications. Critical reviews in food science and nutrition 2016, 56, 817-834, https://doi.org/10.1080/10408398.2012.729231.

96. del Carmen Beristain-Bauza, S.; Mani-López, E.; Palou, E.; López-Malo, A. Antimicrobial activity of whey protein films supplemented with Lactobacillus sakei cell-free supernatant on fresh beef. Food microbiology 2017, 62, 207-211, https://doi.org/10.1016/j.fm.2016.10.024.

97. de Lima Marques, J.; Funck, G.D.; da Silva Dannenberg, G.; dos Santos Cruxen, C.E.; El Halal, S.L.M.; Dias, A.R.G.; Fiorentini, Â.M.; da Silva, W.P. Bacteriocin-like substances of Lactobacillus curvatus P99: characterization and application in biodegradable films for control of Listeria 
monocytogenes in cheese. Food microbiology 2017, $63, \quad$ 159-163, https://doi.org/10.3390/molecules25051134.

98. Peluzio, M.d.C.G.; Martinez, J.A.; Milagro, F.I. Postbiotics: Metabolites and mechanisms involved in microbiota-host interactions. Trends in Food Science \& Technology 2020.

99. Bagde, P.; Nadanathangam, V. Mechanical, antibacterial and biodegradable properties of starch film containing bacteriocin immobilized crystalline nanocellulose. Carbohydrate polymers 2019, 222, 115021, https://doi.org/10.1016/j.carbpol.2019.115021.

100. Silva, D.R.; Sardi, J.d.C.O.; de Souza Pitangui, N.; Roque, S.M.; da Silva, A.C.B.; Rosalen, P.L. Probiotics as an alternative antimicrobial therapy: Current reality and future directions. Journal of Functional Foods 2020, 73, 104080, https://doi.org/10.1016/j.jff.2020.104080.

101. Gbassi, G.K.; Vandamme, T. Probiotic encapsulation technology: from microencapsulation to release into the gut. Pharmaceutics 2012, 4, 149-163, https://doi.org/10.3390/pharmaceutics4010149.

102. Rathore, S.; Desai, P.M.; Liew, C.V.; Chan, L.W.; Heng, P.W.S. Microencapsulation of microbial cells. Journal of Food Engineering 2013, 116, 369-381, https://doi.org/10.1016/j.jfoodeng.2012.12.022.

103. Anwar, F.; Altayb, H.N.; Al-Abbasi, F.A.; Al-Malki, A.L.; Kamal, M.A.; Kumar, V. Antiviral effects of probiotic metabolites on COVID-19. Journal of Biomolecular Structure and Dynamics 2020, 1-10, https://doi/10.1080/07391102.2020.1775123.

104. Koirala, R.; Gargari, G.; Arioli, S.; Taverniti, V.; Fiore, W.; Grossi, E.; Anelli, G.M.; Cetin, I.; Guglielmetti, S. Effect of oral consumption of capsules containing Lactobacillus paracasei LPCS01 on the vaginal microbiota of healthy adult women: a randomized, placebo-controlled, doubleblind crossover study. FEMS microbiology ecology 2020, 96, fiaa084, https://doi.org/10.1093/femsec/fiaa084. 